\title{
THE OBSERVATION OF PREDISSOCIATIONS IN THE OXYGEN MOLECULAR ION BY LOW-ENERGY ELECTRON IMPACT
}

\author{
J. SCHOPMAN and R. LOCHT \\ Département de Chimie Générale et Chimie Physique, Institut de Chimie, Sart Tilman par B-4000 Liège 1, \\ Belgium
}

\begin{abstract}
The kinetic energy distribution of the $\mathrm{O}^{+}$ions formed by dissociative ionization of $\mathrm{O} 2$ has been carefully ex-amined in the range of 0.0 to $1.3 \mathrm{eV}$. In the peak at $600 \mathrm{meV}$ fine structure is observed and interpreted by predissociation. The high energy side of the peak has been ascribed to the predissociation of the ${ }^{2} \Delta_{\mathrm{g}}, \mathrm{B}^{2} \Sigma_{\mathrm{g}}^{-}$and the $\mathrm{c}^{4} \Sigma_{\mathrm{u}}{ }^{-}$states of $\mathrm{O}_{2}^{+}$. The low energy side of the peak is presumably due to the predissociation of the $\mathrm{b}^{4} \Sigma_{\mathrm{g}}{ }^{-}$state or the $\Phi_{\mathrm{u}}$ state of $\mathrm{O}_{2}^{+}$or to autoionizing predissociation.
\end{abstract}

During the last few years much attention has been paid to the dissociation of diatomic molecules. One of the dissociation channels a molecule can choose is the predissociation observed in several neutral and ionized species. Besides the optical spectroscopy methods, predissociations have been investigated by a variety of techniques such as "metastable ion" mass spectrometry $[1,2]$, high resolution translational spectroscopy $[3,4]$ as well as photoelectron spectroscopy $[5,6]$

The dissociation of the oxygen molecular ion has been the subject of several papers. Doolittle et al. [7] obtained the kinetic energy distribution curve of $\mathrm{O}^{+}$from $\mathrm{O}_{2}$ by using photoionization mass spectrometry. Freund [8] and Kieffer et al. [9] studied the kinetic energy carried away by the 0 ions formed by electron impact on $\mathrm{O}_{2}$. These authors ascribed the first broad and structureless peak, with a maximum at $850 \mathrm{meV}$, to $\mathrm{O}^{+}$fragment ions formed by predissociation, although no direct experimental evidence was found for this mechanism. Recently Danby and Eland [5] showed experimentally the existence of a predissociation of $\mathrm{O}_{2}$ by using the photoelectronphotoion coincidence technique.

The purpose of this paper is to report our results obtained for the kinetic energy analysis of the $\mathrm{O}^{+}$ions formed by electron impact on molecular oxygen;

The instrument used, as well as the experimental conditions will be described elsewhere [10]. Briefly, the ions formed in a conventional Nier-type ion source pass through a retarding potential system before entering into a quadrupole mass spectrometer. The ion current is, at fixed electron energy, continuously scanned with respect to the retarding potential or with respect to electron energy at fixed retarding potential. The first derivative of either the retarding curves or the ionization efficiency curves is stored in a multichannel analyser and plotted on an $X-Y$ recorder.

A preliminary report [11] has been devoted to the kinetic energy distribution curve of $\mathrm{O}^{+}$from $\mathrm{O}_{2}$, spread over a broad energy range ( 0 to $12 \mathrm{eV})$. These results will be published elsewhere [10]. In this letter we will limit our discussion to the results obtained in the energy range of 0 to $1.3 \mathrm{eV}$.

An example of a kinetic energy distribution of $\mathrm{O}^{+}$from $\mathrm{O}_{2}$, as observed by the impact of $25 \mathrm{eV}$ electrons, is shown in fig. 1.

The first peak maximum is measured at $0.0 \mathrm{eV}$ coinciding with the maximum of the thermal distribution of the molecular ion $\mathrm{O}_{2}$, taken as the origin of the kinetic energy scale. The second maximum, measured at 600 $\mathrm{meV}$ (and at $850 \mathrm{meV}$ under low resolution and $60 \mathrm{eV}$ electron energy [10]), exhibits a fine structure. The positions of the submaxima, averaged over 30 independent experiments, are listed in table 1 . The structure observed in this peak has to be ascribed to the interaction of stable vibronic states of $\mathrm{O}_{2}$ with the dissociation continuum of other states of this molecular ion. As shown by the underlying continuum in the $600 \mathrm{meV}$ peak, direct dissociation of $\mathrm{O}_{2}$ is observed in the same energy range. 
Fig. 1. Example of a smoothed [10] first differentiated curve of $\mathrm{O}^{+}$from $\mathrm{O}_{2}$ obtained by the impact of $25 \mathrm{eV}$ electrons.

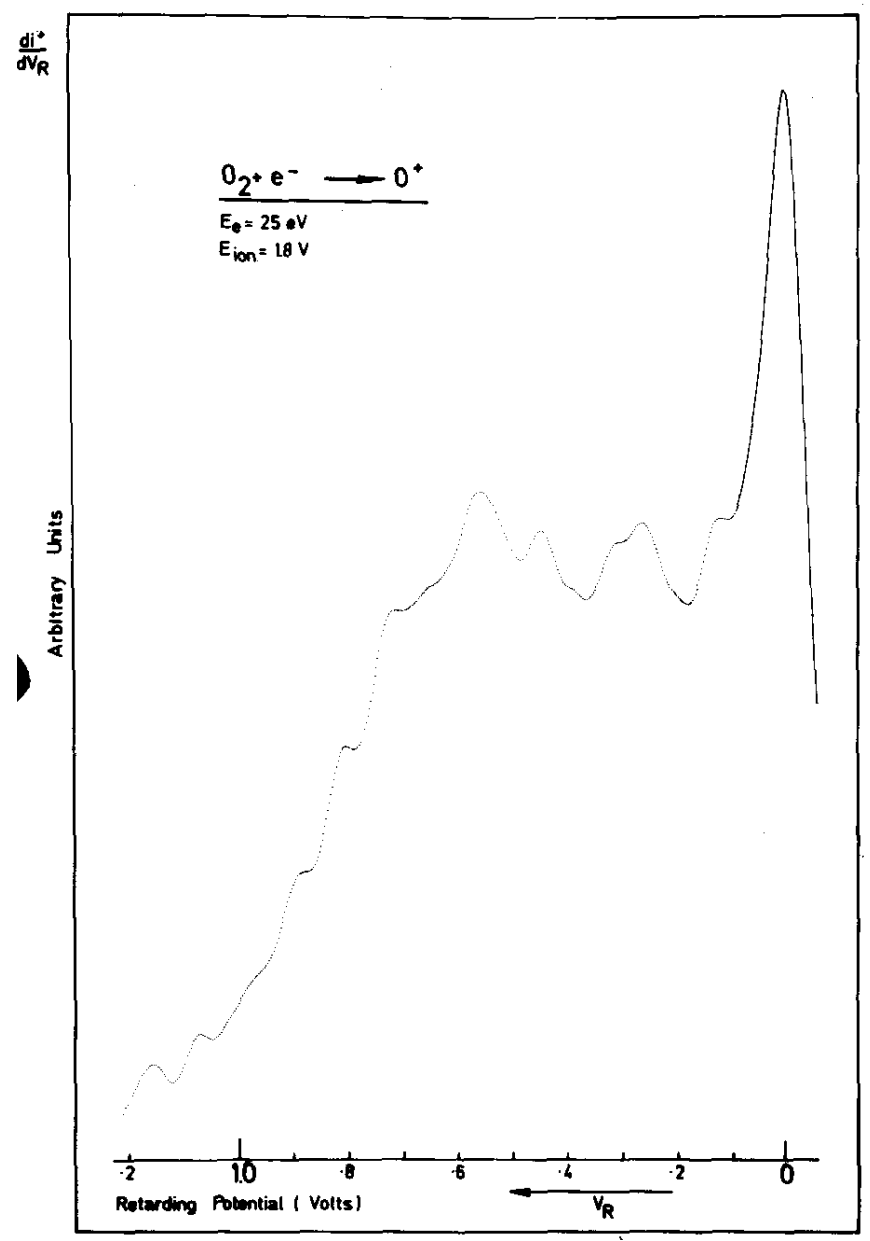

The interpretation given by Doolittle et al. [7], Freund [8] and Kieffer et al. [9] for their structureless peak at $850 \mathrm{meV}$ in the kinetic energy distribution of $\mathrm{O}^{+}$, is the formation of this fragment ion by predissociation of the $\mathrm{B}^{2} \Sigma_{\mathrm{g}}^{-}$state of $\mathrm{O}_{2}$. Danby and Eland [5] showed unequivocally that by photoionization of $\mathrm{O}_{2}$, the $\mathrm{B}^{2} \Sigma_{\mathrm{g}}{ }^{-}$ state of $\mathrm{O}_{2}$ is predissociated from $v^{\prime}=0$ up to $v^{\prime}=5$. However, the kinetic energy carried away by $\mathrm{O}^{+}$formed by predissociation of the $v^{\prime}=0$ level of the $\mathrm{B}^{2} \Sigma_{\mathrm{g}}{ }^{-}$state is calculated at $783 \mathrm{meV}$ (or $1566 \mathrm{meV}$ total kinetic energy) using $\mathrm{IP}_{\mathrm{ad}}\left(\mathrm{O}_{2}^{+}, \mathrm{B}^{2} \Sigma_{\mathrm{g}}\right)=20.296 \mathrm{eV}$ [12] and the dissociation limit of $\mathrm{O}^{+}{ }_{2}\left(\mathrm{X}^{2} \Pi_{\mathrm{g}}\right)$ at $18.73 \mathrm{eV}$ [7]. This interpretation is unable to explain the structure observed on the low energy side of the peak measured at $600 \mathrm{meV}$ at $25 \mathrm{eV}$ electron energy.

In the energy range of interest, let us recall briefly that a carefull analysis of the absorption spectra of Rydberg series has been performed in $\mathrm{O}_{2}$ by Tanaka et al. [13, 14]. In the $\mathrm{He}(\mathrm{II})$ photoelectron spectrum of $\mathrm{O}_{2}$ obtained by Edqvist et al. [12] at least two unassigned peaks of low intensity are detected between the $\mathrm{B}^{2} \Sigma_{\mathrm{g}}{ }^{-}$and the $\mathrm{b}^{4} \Sigma_{\mathrm{g}}{ }^{-}$states of $\mathrm{O}_{2}$. Recently, Jonathan et al. [15], from the photo-electron spectrum of $\mathrm{O}_{2}\left({ }^{1} \Delta_{\mathrm{g}}\right)$, were able to observe the appearance of $\mathrm{O}_{2}$ in the ${ }^{2} \Delta_{\mathrm{g}}$ and the ${ }^{2} \Phi_{\mathrm{u}}$ states for which the molecular parameters are evaluated. We used these parameters in order to calculate the corresponding Morse potential-energy curves shown in fig. 2 . The $\mathrm{b}^{4} \Sigma_{\mathrm{g}}^{-}$, the $\mathrm{B}^{2} \Sigma_{\mathrm{g}}^{-}$and the $\mathrm{c}^{4} \Sigma_{\mathrm{u}}^{-}$states have also been drawn.

In the following discussion we shall consider the total kinetic energy (twice the measured kinetic energy carried away by the fragments), quantity which is immediately comparable to the vibrational structure observed in photoelectron spectroscopy (see table 1). 
In addition to the dissociation limit observed at $17.25 \mathrm{eV}$ for the first ion-pair process [16], the plot of the threshold energies as a function of the retarding potential [10] shows, at least, three dissociation limits lying in the ion-kinetic energy range from $0.0 \mathrm{meV}$ to $2740 \mathrm{meV}$, i.e., $18.73 \mathrm{eV}, 20.60 \mathrm{eV}$ and $22.06 \mathrm{eV}$ [7] characterized by the following processes:

$$
\begin{aligned}
& \mathrm{O}_{2}^{+} \rightarrow \mathrm{O}\left({ }^{3} \mathrm{P}\right)+\mathrm{O}^{+}\left({ }^{4} \mathrm{~S}\right), \\
& \mathrm{O}_{2}^{+} \rightarrow \mathrm{O}\left({ }^{1} \mathrm{D}\right)+\mathrm{O}^{+}\left({ }^{4} \mathrm{~S}\right), \\
& \mathrm{O}_{2}^{+} \rightarrow \mathrm{O}\left({ }^{3} \mathrm{P}\right)+\mathrm{O}^{+}\left({ }^{2} \mathrm{D}\right) .
\end{aligned}
$$

Nine repulsive or quasi-repulsive curves converge to the lowest dissociation limit at $18.73 \mathrm{eV}$ [17]. Considering the selection rules for predissociation [18] and the kinetic energy measurements, at least the $\mathrm{b}^{4} \Sigma_{\mathrm{g}}^{-},{ }^{2} \Delta_{\mathrm{g}}$ and the $\mathrm{B}^{2} \Sigma_{\mathrm{g}}{ }^{-}$states could be involved for the interpretation of the fine structure observed in the $0.0-1540 \mathrm{meV}$ kinetic energy range. However, the ${ }^{2} \Phi_{\mathrm{u}}$ state cannot be excluded a priori.

Table 1 Positions of the submaxima observed in the first differentiated ion-retarding curve of $\mathrm{O}^{+}$from $\mathrm{O}_{2}{ }^{a)}$ The

\begin{tabular}{|c|c|c|c|c|}
\hline $\mathrm{KE}_{\mathrm{exp}}(\mathrm{meV})$ & $\mathrm{KE}_{\text {calc }}(\mathrm{meV})$ & $v^{\prime}$ & State & Remarks \\
\hline 0 & 40 & 1 & $\left({ }^{2} \Phi_{\mathrm{u}}\right)$ & $\mathrm{b}^{4} \sum_{\mathrm{g}}^{-1} \mathrm{v}^{\prime}=4 ; \mathrm{KE}=0$ \\
\hline $170 \pm 30$ & 150 & 2 & & $\mathrm{v}^{\prime}=5 ; \mathrm{KE}=120$ \\
\hline $254 \pm 20$ & 260 & 3 & & $v^{\prime}=6 ; K E=240$ \\
\hline $346 \pm 30$ & 370 & 4 & & \\
\hline $516 \pm 20$ & 480 & 5 & & \\
\hline \multirow[t]{2}{*}{$634 \pm 30$} & 590 & 6 & & \\
\hline & 700 & 7 & & \\
\hline $780 \pm 60$ & 810 & 8 & & \\
\hline $916 \pm 30$ & 920 & 9 & & \\
\hline \multirow[t]{2}{*}{$1020 \pm 20$} & $\int 1030$ & 10 & ${ }^{2} \Delta_{g}$ & \\
\hline & 1060 & 0 & & \\
\hline \multirow[t]{2}{*}{$1140 \pm 30$} & $\int 1040$ & 11 & & \\
\hline & 1070 & 1 & & \\
\hline $1296 \pm 30$ & 1280 & 2 & & \\
\hline $1440 \pm 20$ & 1390 & 3 & & \\
\hline \multirow[t]{2}{*}{$1540 \pm 30$} & $\int 1500$ & 4 & & \\
\hline & 1566 & 0 & $\mathrm{~B}^{2} \sum_{\mathrm{g}}^{-}$ & \\
\hline $1694 \pm 40$ & 1740 & 1 & & \\
\hline $1858 \pm 40$ & 1836 & 2 & & \\
\hline $1968 \pm 30$ & 1963 & 3 & & \\
\hline $2058 \pm 20$ & 2085 & 4 & & \\
\hline $2198 \pm 30$ & 2200 & 5 & & \\
\hline $2354 \pm 50$ & $?$ & (6) & & \\
\hline $2536 \pm 30$ & 2522 & 0 & $\mathrm{c}^{4} \sum_{\mathrm{u}}^{-}$ & \\
\hline $2740 \pm 60$ & 2814 & 1 & & \\
\hline
\end{tabular}

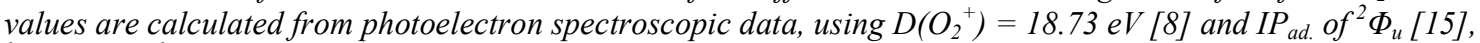
${ }^{2} \Delta_{g}[15], B^{2} \sum_{g}^{-}[12]$ and $c^{4} \sum_{u}^{-}[12]$

a) Quoted values in column 1 correspond to twice the energy measured by the position of the submaxima.

The sequence ranging from 1020 to $2740 \mathrm{meV}$ will be considered first (see table 1). From energetic considerations, the $\mathrm{O}^{+}$ions have to be formed by predissociation of the upper vibronic states of $\mathrm{O}_{2}^{+}$, i.e., the ${ }^{2} \Delta_{\mathrm{g}}$ and the $\mathrm{B}^{2} \Sigma_{\mathrm{g}}{ }^{-}$states, through at least one unstable electronic state converging to the dissociation limit at 18.73 $\mathrm{eV}$.

The fairly good agreement between the experimental and the calculated values of $v^{\prime}$ for the $\mathrm{B}^{2} \Sigma_{\mathrm{g}}{ }^{-}$state confirms the photoelectron-photoion coincidence measurements performed by Danby and Eland [5]. However, the photoelectron-photoion coincidences have been observed up to the $v^{\prime}=4$ vibrational level of the $\mathrm{B}^{2} \Sigma_{\mathrm{g}}{ }^{-}$state. 
From the present work this state is predissociated at least up to $v^{\prime}=5$ or 6 . Although the $v^{\prime}=6$ level of the $\mathrm{B}^{2} \Sigma_{\mathrm{g}}{ }^{-}$ state is observed in the photoelectron spectrum [12], no value of its ionization potential is given by Edqvist et al. However, the intensity of the bands correspond-ing to the $v^{\prime}=5$ and $v^{\prime}=6$ levels represent $8.5 \%$ and $3.8 \%$ of the $v^{\prime}=1$ transition. The low intensity of these transitions could be responsible for the lack of photoelectronphotoion coincidences for these levels.

Fig. 2. Potential energy curves of $\mathrm{O}_{2}{ }^{+}$as given by Gilmore [17] and calculated by the Morse equation using the param-eters given by Jonathan et al. [15].

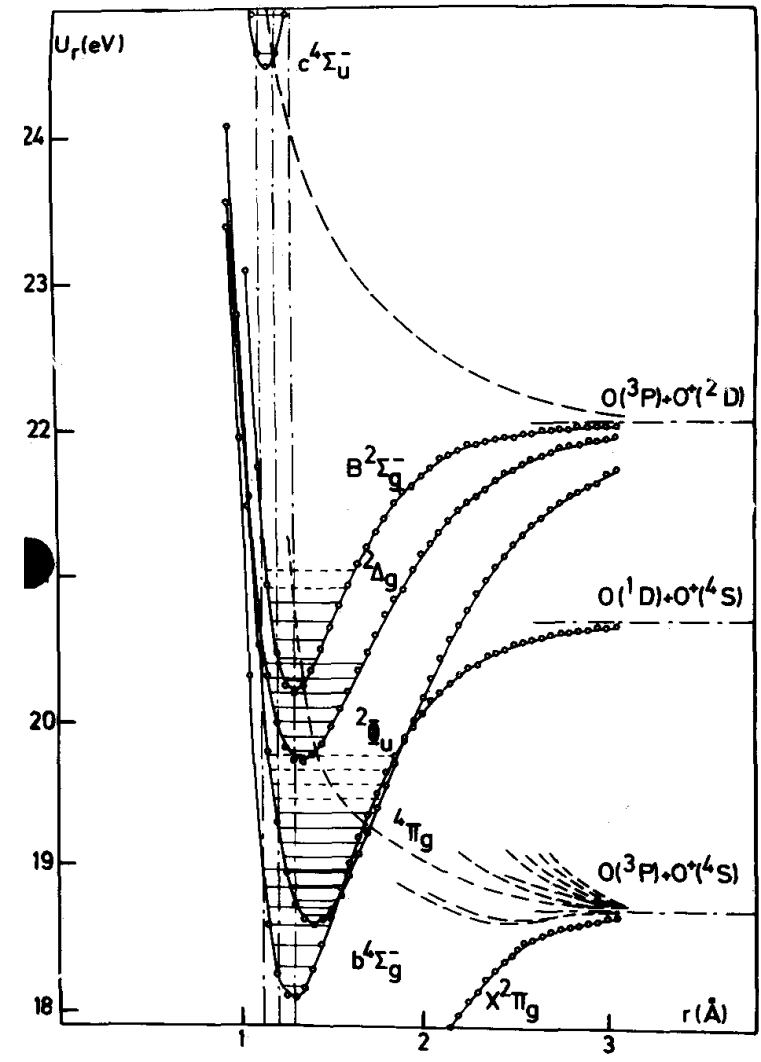

The appearance potential of $\mathrm{O}^{+}$ions formed by predissociation of the $v^{\prime}=0$ vibrational level of the ${ }^{2} \Delta_{\mathrm{g}}$ state of $\mathrm{O}_{2}{ }^{+}$should be measured at $19.79 \mathrm{eV}$, i.e., the adiabatic ionization potential of the ${ }^{2} \Delta_{\mathrm{g}}$ state [15]. The minimum kinetic energy involved in the predissociation taking place at the $18.73 \mathrm{eV}$ dissociation limit, should be $1060 \mathrm{meV}$. A submaximum is measured at $(1020 \pm 20) \mathrm{meV}$. Furthermore, as a preliminary result of a work under progress, the ionization efficiency curves of $\mathrm{O}^{+}$recorded at retarding potentials between 200 and $600 \mathrm{mV}$ exhibit a threshold at $(19.8 \pm 0.2) \mathrm{eV}$ which is in satisfactory agreement with the value of the adiabatic IP of $\mathrm{O}_{2}{ }^{+}$ $\left({ }^{2} \Delta_{\mathrm{g}}\right)$. Finally, table 1 shows a fairly good agreement between the measured and calculated total kinetic energies involved in the predissociation.

Considering the selection rules for non-radiative transitions [18] and the symmetry of the repulsive states converging to the $18.73 \mathrm{eV}$ dissociation limit, both the ${ }^{2} \Delta_{\mathrm{g}}$ and the B ${ }^{2} \Sigma_{\mathrm{g}}{ }^{-}$states could be predissociated by the ${ }^{4} \Pi_{\mathrm{g}}$ state.

Two submaxima are measured at $2536 \mathrm{meV}$ and at $2740 \mathrm{meV}$ and could be assigned to the predissociation of the $v^{\prime}=0$ and $v^{\prime}=1$ levels of the $\mathrm{c}^{4} \Sigma_{\mathrm{u}}{ }^{-}$state of $\mathrm{O}_{2}{ }^{+}$. The adiabatic ionization potential of the $\mathrm{c}^{4} \Sigma_{\mathrm{u}}{ }^{-}$state of $\mathrm{O}_{2}^{+}$is measured at $24.577 \mathrm{eV}$ by photoelectron spectroscopy [12]. The dissociation of $\mathrm{O}_{2}^{+}$by process (3) is calculated at $22.06 \mathrm{eV}$ [7]. The total kinetic energy involved in the process, when produced by predissociation of the $v=0$ level of the $\mathrm{c}^{4} \Sigma_{\mathrm{u}}{ }^{-}$state is given by the energy difference between $24.577 \mathrm{eV}$ [12] of the $\mathrm{c}^{4} \Sigma_{\mathrm{u}}{ }^{-}\left(v^{\prime}=0\right)$ state and $22.055 \mathrm{eV}$ [7], i.e., $2522 \mathrm{meV}$. This is in good agreement with the measured total kinetic energy of $(2536 \pm 30) \mathrm{meV}$. Support to this interpretation could be found in the photoelectron spectrum of the $\mathrm{c}^{4} \Sigma_{\mathrm{u}}^{-}$state which shows a sudden break-off in the vibrational structure [12]. Furthermore Rydberg absorption series converging to the two first levels of the $\mathrm{c}^{4} \Sigma_{\mathrm{u}}{ }^{-}$of $\mathrm{O}_{2}{ }^{+}$have been identified [19], although the 
emission from only one level has been observed [20].

Finally the sequence ranging from 0.0 to $916 \mathrm{meV}$ is to be considered. If only molecular ion states are considered in this energy range, the ${ }^{2} \Phi_{\mathrm{u}}$ and/or the $\mathrm{b}^{4} \Sigma_{\mathrm{g}}{ }^{-}$states have to be involved. The observed fine structure is due to the predissociation of one or both states by a repulsive or a quasi-repulsive state of $\mathrm{O}_{2}$ leading to the dissociation limit at $18.73 \mathrm{eV}$. Referring to table 1 , the vibrational sequence of the ${ }^{2} \Phi_{\mathrm{u}}$ and the $\mathrm{b}^{4} \Sigma_{\mathrm{g}}{ }^{-}$states have been listed versus the position of the submaxima as measured in the kinetic energy distribution of $\mathrm{O}^{+}$from $\mathrm{O}_{2}$. The agreement between measured and calculated values is satisfactory in this energy range, as far as the ${ }^{2} \Phi_{\mathrm{u}}$ state is considered.

However, taking into account the selection rule for non-radiative transitions [18], related to the symmetry of the repulsive states which could be involved, the predissociation of the ${ }^{2} \Phi_{u}$ state is strong-ly forbidden. Considering the potential energy curves given by Gilmore [17], only the ${ }^{2} \Sigma_{\mathrm{g}}{ }^{+}$, the ${ }^{4} \Sigma_{\mathrm{g}}{ }^{+}$and the ${ }^{4} \Pi_{\mathrm{g}}$ state could predissociate the ${ }^{2} \Phi_{\mathrm{u}}$ state. If such was the case the $\Delta \Lambda=0, \pm 1$ as well as the parity and the spin conservation rules would be violated simultaneously.

The second possible interpretation is the predis-sociation of the $\mathrm{b}^{4} \Sigma_{\mathrm{g}}{ }^{-}$state of $\mathrm{O}_{2}^{+}$. However, the first vibrational level lying nearest to the dissociation limit is the $v^{\prime}=4$ level at $18.721 \mathrm{eV}$ [12] and the $\mathrm{b}^{4} \Sigma_{\mathrm{g}}^{-}$state is populated up to $v^{\prime}=6$ by direct Franck-Condon transition. The population of higher vibrational levels through collisions in the ion-chamber could be regarded as improbable in the present experimental conditions. By this way, at least three vibrational levels could be predissociated.

To interpret the vibrational sequence observed in the low energy side of the $600 \mathrm{meV}$ peak, three alter-natives are proposed: (i) the population of higher vi-brational levels of the $\mathrm{b}^{4} \Sigma_{\mathrm{g}}{ }^{-}$state of $\mathrm{O}_{2}{ }^{+}$through radiative transitions from Rydberg states, or (ii) the autoionizing predissociation, i.e., the predissociation of a superexcited state of $\mathrm{O}_{2}$ through an unstable molecular ion state of $\mathrm{O}_{2}^{+}$. A Rydberg state of $\mathrm{O}_{2}$, characterized by a $\Sigma$ or $\Pi$ symmetry and converging to the ${ }^{2} \Phi_{\mathrm{u}}$ state of $\mathrm{O}_{2}^{+}$, could be predissociated by a ${ }^{2} \Sigma$ or ${ }^{4} \Sigma$ unstable or quasi-unstable state of $\mathrm{O}_{2}^{+}$ and finally (iii) the predissociation of the ${ }^{2} \Phi_{\mathrm{u}}$ state of $\mathrm{O}_{2}^{+}$could not be excluded.

\section{Acnowledgements}

We wish to thank Professor J. Momigny for helpful suggestions and Dr. N. Jonathan for making available his results prior to publication. The financial support of the Fonds de la Recherche Fondamentale Collective is gratefully acknowledged. One of us (J.S.) acknowledges the Patrimoine de l'Université de Liège for a grant.

\section{References}

[1] H. Wankenne and J. Momigny, Intern. J. Mass Spectrom. Ion Phys. 7(1971)227.

[2] G. Mathieu, H. Wankenne and J. Momigny, Chem. Phys. Letters 17 (1972) 260; 21 (1973) 606.

[3] P.G. Fournier, T.R. Govers, C.A. van de Runstraat, J. Schoprnan and J. Los, Chem. Phys. Letters 9 (1971) 426; J. Phys. (Paris) 33 (1972) 755.

[4] G. Mathieu, Doctoral thesis, Université de Liège (1974).

[5] C.J. Danby and J.H.D. Eland, Intern. J. Mass Spectrom. Ion Phys. 8(1972) 153.

[6] J. Delwiche, P. Natalis, J. Momigny and J.E. Collin, J.Electron Spectry. 1 (1972/73) 219.

[7] P.H. Doolittle, R.I. Schoen and K.E. Schubert, J. Chem. Phys. 49(1968)5108.

[8] R.S. Freund, J. Chem. Phys. 54 (1971) 3125.

[9] L.J. Kieffer, G.M. Lawrence and J.M. Slater, VII ICPEAC, Amsterdam, 1971 (North-Holland, Amsterdam, 1971) p. 574. 
Published in: Chemical Physics Letters (1974), vol. 26, pp. 596-600

Status: Postprint (Author's version)

[10] R. Locht and J. Schoprnan, to be published.

[11] J. Schoprnan and R. Locht, VIII ICPEAC, Beograd, 1973 (Inst. Phys., Beograd, 1973) p. 424.

[12] O. Edqvist, E. Lindholm, L.E. Selin and L. Asbrink, Physica Scripta 1 (1970) 25.

[13] Y. Tanaka and T. Takamine, Sci. Papers Inst. Phys. Chem. Res. Tokyo 39 (1942) 437.

[14] K. Yoshino and Y. Tanaka, J. Chem. Phys. 48 (1968)4859.

[15] N. Jonathan, A. Morris, M. Okuda, K.J. Ross and D.J. Smith, J. Chem. Phys. 54 (1971) 4954; Faraday Discussions Chem. Soc. 54 (1972) 64; XI Intern. Symp. on Free Radicals, Berchtesgaden-Kסnigssee (1973).

[16] R. Locht and J. Momigny, Intern. J. Mass Spectrom. Ion Phys. 7(1971) 121.

[17] F.R. Gilmore, J. Quant. Spectry. Radiative Transfer 5 (1965) 369.

[18] G. Herzberg, Molecular spectra and molecular structure. I. Spectra of diatomic molecules, 2nd Ed. (Van Nostrand, Princeton, 1950) p. 416.

[19] K. Codling and R.P. Madden, J. Chem. Phys. 42 (1965) 3935.

[20] F.J. Leblanc, J. Chem. Phys. 38 (1963) 487. 